\section{Postharvest Quality of 'Thompson Seedless' Grapes after Insecticidal Controlled-atmosphere Treatments}

\author{
Miguel H. Ahumada ${ }^{1}$, Elizabeth J. Mitcham ${ }^{2}$, and Denise G. Moore $^{3}$ \\ Department of Pomology, University of California, Davis, CA 95616
}

Additional index words. Vitis vinifera, insect quarantine, carbon dioxide

\begin{abstract}
Non-SO $\mathrm{S}_{2}$-fumigated 'Thompson Seedless' table grapes (Vitis vinifera $\mathrm{L}$.) were stored at 5 or $20{ }^{\circ} \mathrm{C}$ for 6 and 4.5 days, respectively, in air or one of four insecticidal controlled atmospheres (ICA); $0.5 \% \mathrm{O}_{2}+35 \% \mathrm{CO}_{2} ; 0.5 \% \mathrm{O}_{2}+45 \% \mathrm{CO}_{2} ; 0.5 \% \mathrm{O}_{2}+55 \%$ $\mathrm{CO}_{2} ;$ or $100 \% \mathrm{CO}_{2}$. The fruit were evaluated for weight loss, berry firmness, soluble solids concentration (SSC), titratable acidity, berry shattering, rachis browning, berry browning, and volatiles (acetaldehyde and ethanol). Fruit quality was not affected at $5^{\circ} \mathrm{C}$ with the exception of greater rachis browning in fruit treated with $0.5 \% \mathrm{O}_{2}+45 \% \mathrm{CO}_{2}$. At 20 ${ }^{\circ} \mathrm{C}$, ICA treatments maintained greener rachis compared to the air control; however, SSC was reduced in the fruit treated with $55 \%$ and $100 \% \mathrm{CO}_{2}$. At both temperatures, ICA induced the production of high levels of acetaldehyde and ethanol. Ethanol concentrations were two-thirds lower at $5{ }^{\circ} \mathrm{C}$ than at $20^{\circ} \mathrm{C}$. Consumer preference was negatively affected by some ICA treatments for grapes kept at $20^{\circ} \mathrm{C}$, but not by any of the treatments at $5{ }^{\circ} \mathrm{C}$. Preliminary data for mortality of omnivorous leafroller pupae (Platynota stultana Walshingham), western flower thrips (Frankliniella occidentalis Pergande) adults and larvae, and pacific spider mite (Tetranychus pacificus McGregor) adults and larvae indicate that many of the ICA treatments would provide significant insect control.
\end{abstract}

Methyl bromide, a fumigant widely used for insect quarantine treatment of fresh commodities, is scheduled for phaseout in the United States in 2001. There is great interest in finding alternative treatments. Controlled atmospheres (CA) with elevated $\mathrm{CO}_{2}$, reduced $\mathrm{O}_{2}$ concentrations, or both could be an effective treatment against some insect pests (Carpenter and Potter, 1994; Carpenter et al., 1993; Kader and Ke, 1994; Ke and Kader, 1992). CA are effective for control of many insects that attack stored grain, especially when $\mathrm{CO}_{2}$ is $>50 \%$ and $\mathrm{O}_{2}$ is < $1 \%$ (Fleurat-Lassard, 1990; Jayas et al., 1991). CA are very effective for insect control in dried fruit and nuts (Soderstrom and Brandl, 1990). The feasibility of CA for controlling insects in fresh fruit and vegetables varied according to the temperature at which these commodities could be stored without injury and also according to their response to high $\mathrm{CO}_{2}$ or low $\mathrm{O}_{2}$ (Aharoni et al., 1979, 1981; Batchelor et al., 1985; Prange and Lidster, 1992).

Previous CA research on table grapes has focused on $\mathrm{CA}$ as an alternative to $\mathrm{SO}_{2}$ for decay control and for long-term storage

Received for publication 25 Sept. 1995. Accepted for publication 30 Mar. 1996. This study was funded in part by a grant from the California Table Grape Commission. We thank Juno Cespedes and Bil Biasi for their technical assistance throughout these experiments. The cost of publishing this paper was defrayed in part by the payment of page charges. Under postal regulations, this paper therefore must be hereby marked advertisement solely to indicate this fact.

${ }^{1}$ Graduate Student. Current address: Adcon Telemetry, Boca Raton, Fla.

${ }^{2}$ Assistant Specialist and Pomologist.

${ }^{3}$ Laboratory Assistant.
(Harvey and Uota, 1978; Nelson, 1969; Yahia et al., 1983). However, the response of 'Thompson Seedless' grapes to short-term high- $\mathrm{CO}_{2}$ treatments for control of insects is unknown. After 133 days of storage at $-1.1^{\circ} \mathrm{C}$, Nelson (1969) observed an increase in berry and stem browning, and development of an off-flavor with $\mathrm{CO}_{2}>15 \%$. High soluble solids concentration (SSC) was correlated with browning of the stem and the berries. Although Nelson (1969) found that $15 \% \mathrm{CO}_{2}$ provided disease control similar to $\mathrm{SO}_{2}$, he concluded that the threshold of $\mathrm{CO}_{2}$ tolerance for $>4$ months storage appeared to be between $10 \%$ and $15 \%$ $\mathrm{CO}_{2}$.

Storage of 'Italia' grapes at $0{ }^{\circ} \mathrm{C}$ under $0.5 \% \mathrm{O}_{2}$ in $\mathrm{N}_{2}$ resulted in good control of Botrytis cinerea Pers.:Fr during 4 months of storage (Cimino and Zapanangeli, 1990). However, storage of grapes at $2 \%$ or $21 \% \mathrm{O}_{2}$ with $0 \%, 2 \%$, or $5 \% \mathrm{CO}_{2}$ induced stem darkening during 1 month of storage (Laszlo, 1985). Although there was no difference in grape palatability in this study, the $\mathrm{SO}_{2}$-fumigated control had less decay than CA-stored grapes. Claypool and Allen (1947) stored grapes for 10 days at 18 or $4.5^{\circ} \mathrm{C}$ under $21 \%, 15 \%, 10 \%$, $5 \%$, and $2.5 \% \mathrm{O}_{2}$. The reduced $\mathrm{O}_{2}$ levels did not produce any noticeable change in the ripeness or the flavor of the berries nor did the low $\mathrm{O}_{2}$ level affect berry shattering. Low- $\mathrm{O}_{2}(2.5 \%)$ storage provided decay control, but as the $\mathrm{O}_{2}$ concentration increased, fungal growth developed on the stems. Although these studies do not indicate tremendous promise for longterm storage of grapes in CA, the data indicate that grapes may tolerate short-term exposure to CA.

The objective of this study was to determine the response of 'Thompson Seedless' table grapes to short-term exposure to high$\mathrm{CO}_{2}$ and low- $\mathrm{O}_{2}$ atmospheres that have potential to provide quarantine security against insects and mites. Preliminary testing of these atmospheres for mortality of omnivorous leafroller (OLR) pupae, western flower thrips (WFT) adults and larvae, and pacific spider mite (PSM) adults and larvae also was conducted to determine the potential of these treatments for quarantine control of these important California table grape pests.

\section{Materials and Methods}

Non- $\mathrm{SO}_{2}$-fumigated 'Thompson Seedless' grapes were obtained from the southern San Joaquin Valley of California on $23 \mathrm{Aug}$. and from the central San Joaquin Valley on 15 Sept. 1994 for two separate experiments. The fruit was transported the day of harvest in an air-conditioned vehicle to the Univ. of California at Davis and stored overnight at $5{ }^{\circ} \mathrm{C}$, before clusters were selected for uniformity; condition of the pedicel, rachis, and capstem; and cluster size, greenness, and absence of decayed berries. Defective berries were trimmed from clusters and several clusters were selected to give $\approx 1.5 \mathrm{~kg}$ for each of four replications. Preliminary experiments with insects and mites guided the selection of atmospheres, temperatures, and treatment times.

Each replication was placed in a 9.5-L glass container. In the first experiment, fruit in the jars were stored at $20^{\circ} \mathrm{C}$ for 4.5 days under the following flow-through atmospheres: air $\left(21 \% \mathrm{O}_{2}+0.03 \% \mathrm{CO}_{2}\right) ; 0.5 \% \mathrm{O}_{2}+35 \% \mathrm{CO}_{2}$; $0.5 \% \mathrm{O}_{2}+45 \% \mathrm{CO}_{2} ; 0.5 \% \mathrm{O}_{2}+55 \% \mathrm{CO}_{2}$; and $100 \% \mathrm{CO}_{2}$ (balance $\mathrm{N}_{2}$ for all, except air). In the second experiment, fruit were stored at 5 ${ }^{\circ} \mathrm{C}$ for 6 days. Flow-through atmospheres were identical to those used in the first experiment. After 4.5 or 6 days, fruit were transferred to air at 20 or $5{ }^{\circ} \mathrm{C}$, respectively, and quality evaluations began $8 \mathrm{~h}$ later. The remaining fruit were transferred to $0^{\circ} \mathrm{C}$ and quality was evaluated after 3 or 10 days of storage.

Quality evaluations. The following objective measurements were made immediately after harvest, $8 \mathrm{~h}$ after removal from the insecticidal controlled atmospheres (ICA), and after 3 days storage in air at $0{ }^{\circ} \mathrm{C}$. The skin was removed from the side of each of 10 berries per replication using a razor blade and resistance to compression (with a 4.8-mm-diameter plunger) was measured using a Univ. of California fruit firmness tester (Western Industrial Supply Co., San Francisco). Juice was extracted from 10 berries per replication with a hand-press juicer. Percent SSC was measured with a temperature-compensated refractometer (American Optical Corp., Buffalo, N.Y.). Titratable acidity (TA) was measured by titrating $4 \mathrm{~g}$ of juice to $\mathrm{pH} 8.2$ using an automatic titrator (Radiometer, Copenhagen, Denmark). Tartaric acid equivalents were calculated to give percent TA. An aliquot of juice was frozen at $-40{ }^{\circ} \mathrm{C}$ for later volatile analysis. Berry shattering was determined by the percentage of berries per cluster that separated during $2 \mathrm{~s}$ of moderate shaking in a paper bag. The total number of berries per cluster was 
estimated in the $20{ }^{\circ} \mathrm{C}$ experiment, based on the average weight per berry calculated from a 10-berry sample for each cluster and the total cluster weight. In the $5{ }^{\circ} \mathrm{C}$ experiment, the number of berries per cluster were counted. Clusters were subjectively evaluated for rachis and berry browning.

Volatile analysis. Ethanol and acetaldehyde concentration of grape juice were determined by the method of Davis and Chace (1969) with some modifications as described by Ke et al. (1991b). Five milliliters of juice was incubated $1 \mathrm{~h}$ at $65^{\circ} \mathrm{C}$ in a septum-capped tube. A 1-mL sample from the headspace gas was analyzed for acetaldehyde and ethanol concentration using a gas chromatograph (model GC-9 AM; Shimadzu, Kyoto, Japan) with a flame ionization detector $\left(250^{\circ} \mathrm{C}\right)$ and a 5\% carbowax on 60/80 Carbopack column (Supelco, Bellefonte, Pa.). Volatiles were quantified by comparison to known standards and the concentration in juice samples expressed as $\mu \mathrm{L} \cdot \mathrm{L}^{-1}$.

Consumer preference analysis. The fruit were presented to a consumer panel for preference testing 3 days after transfer to air storage at $0^{\circ} \mathrm{C}$. Testing was conducted on campus and consumers were asked to participate only if they liked grapes. A tray was placed before each consumer with randomized cups containing three berries each with one cup per treatment. Cups were presented in a circle for both experiments. For the $20^{\circ} \mathrm{C}$ experiment, a total of 53 consumers participated. Of those, 25 were female and 28 male. The age ranged from 17 and 72 years, with a mean of 32 . Grapes had been purchased or eaten by 23 of the participants within the last week. For the $5^{\circ} \mathrm{C}$ experiment, a total of 58 consumers participated. Of these, 33 were female and 25 male. The age ranged from 16 to 48 years, with a mean of 26 . Grapes had been purchased or eaten by 29 of the participants within the last week. Consumers were instructed to taste each berry in the cups and to treat the cup as one sample. The consumers were instructed to rank the samples in order of preference from most to least preferred.

Insect mortality tests. Omnivorous leafrollers (OLR) were raised on an artificial diet based on lima beans (Phaseolus lunatus L.) (Yokoyama et al., 1987) in an incubator at $27^{\circ} \mathrm{C}$. Pupae were collected into small plastic cups $(29.56 \mathrm{~mL})$ with mesh lids to allow for gas exchange. Pacific spider mites (PSM) were raised on cotton (Gossypium hirsutum L.) plants. Individual leaves were visually inspected for presence and mortality of mites before CA treatments and dead mites were removed. Leaves were placed in plastic cups as described for OLR. Western flower thrips (WFT) were collected from greenhouse-grown alfalfa (Medicago sativa L.) flowers with a known population of WFT. Flowers were placed in mesh bags made of polyester (107$\mu \mathrm{m}$ pores). Insects and mites in cups or bags were placed in 3.8-L jars under flow-through atmospheres similar to those used in the grape studies. These experiments were conducted separately from the grape experiments but under the same conditions.
Statistical analysis. For the grape experiment, the design was completely randomized with four replications per treatment. The grape data were analyzed using the General Linear Models procedure (SAS Inst., Cary, N.C.), while the consumer preference data were analyzed using the Newell-MacFarlane twofactor ranked analysis of variance (Newell and MacFarlane, 1987).

\section{Results}

The ICA treatments at 20 and $5{ }^{\circ} \mathrm{C}$ did not affect fruit weight loss, firmness, TA, berry browning, or berry shattering (data not shown).

ICA treatment at $20^{\circ} \mathrm{C}$. Grapes treated for 4.5 days at $20^{\circ} \mathrm{C}$ in air had considerable rachis browning (Table 1). Fruit in ICA at $20^{\circ} \mathrm{C}$ had significantly less rachis browning than control fruit in air (Table 1) and no decay (data not shown). Grapes treated with $0.5 \% \mathrm{O}_{2}+55 \%$ $\mathrm{CO}_{2}$ or with $0 \% \mathrm{O}_{2}+100 \% \mathrm{CO}_{2}$ had significantly lower SSC than control fruit in air. SSC did not show significant differences after 3 days of storage at $0^{\circ} \mathrm{C}$ (data not shown), while rachis browning was worse (Table 1). All ICA treatments resulted in an accumulation of acetaldehyde and ethanol (Fig. $1 \mathrm{~A}$ and B). Ethanol concentrations decreased in fruit from all ICA treatments during 3 days of storage in air at $0{ }^{\circ} \mathrm{C}$ (Fig. 1A), while acetaldehyde concentration continued to increase in fruit treated with $0.5 \% \mathrm{O}_{2}+35 \%$ or $45 \% \mathrm{CO}_{2}$, while remaining unchanged in fruit from other treatments (Fig. 1B).

ICA treatment at $5{ }^{\circ} \mathrm{C}$. ICA treatments showed few negative affects on grapes treated for 6 days at $5{ }^{\circ} \mathrm{C}$. Only rachis browning was significantly affected by the treatments (Table 1). Grapes held under $100 \% \mathrm{CO}_{2}$ or with $0.5 \%$ $\mathrm{O}_{2}+45 \% \mathrm{CO}_{2}$ had more rachis browning upon removal from the ICA treatment than control grapes held in air. However, these differences did not persist after 3 days (Table 1 ) or 10 days (data not shown) storage at $0{ }^{\circ} \mathrm{C}$. Acetaldehyde and ethanol accumulated in ICA-treated grapes (Fig. $1 \mathrm{C}$ and D). Ethanol concentration changed little after transfer to air at $0{ }^{\circ} \mathrm{C}$ (Fig.
1C). Acetaldehyde concentration continued to increase after transfer to air at $0{ }^{\circ} \mathrm{C}$ and the concentration in fruit treated with $0.5 \% \mathrm{O}_{2}+$ $55 \% \mathrm{CO}_{2}$ increased to higher levels than in fruit treated with other atmospheres (Fig. 1D).

Consumer preference analysis. The consumer preference analysis produced little significant difference at either temperature. At 20 ${ }^{\circ} \mathrm{C}$, only grapes treated with $0.5 \% \mathrm{O}_{2}+55 \%$ $\mathrm{CO}_{2}$ were preferred less than the grapes treated with air, but were not significantly different from the grapes from other ICA treatments (Table 2). However, at $5{ }^{\circ} \mathrm{C}$ grapes treated with $0.5 \% \mathrm{O}_{2}+55 \% \mathrm{CO}_{2}$ were preferred over grapes treated with $100 \% \mathrm{CO}_{2}$, but were not significantly different from air-stored fruit or other ICA treatments (Table 2).

Insect mortality. All specimens of the three species tested died after 6 days at $5^{\circ} \mathrm{C}$ in $100 \%$ $\mathrm{CO}_{2}$ or $0.5 \% \mathrm{O}_{2}+55 \% \mathrm{CO}_{2}$ (Table 3). After 6 days at $5{ }^{\circ} \mathrm{C}$ in $0.5 \% \mathrm{O}_{2}+45 \% \mathrm{CO}_{2}$, OLR pupae and WFT adults died, while mortality of WFT larvae was $98 \%$ and that of PSM was $>90 \%$. After 4.5 days at $20^{\circ} \mathrm{C}, 100 \%$ mortality was attained in all ICA atmospheres for all species tested (data not shown). Mortality in air ranged from $4 \%$ to $22 \%$.

\section{Discussion}

Insecticidal controlled atmospheres had little negative effect on the quality of 'Thompson Seedless' grapes, particularly at $5{ }^{\circ} \mathrm{C}$. Nelson (1979) indicated that browning of the rachis is considered a secondary symptom of water loss, especially at high temperatures. Water loss at $20{ }^{\circ} \mathrm{C}$ may have contributed to rachis browning, yet storage in ICA appeared to reduce browning while the grapes were in ICA. Laszlo (1985) found no difference in the rachis condition and firmness of table grapes exposed to $1 \%, 2 \%, 3 \%$, or $21 \% \mathrm{O}_{2}$ and $0 \%$, $1 \%, 5 \%$, or $10 \% \mathrm{CO}_{2}$ at $0{ }^{\circ} \mathrm{C}$. Yahia et al. (1983) found no significant differences in $\mathrm{pH}$, TA, or firmness of 'Thompson Seedless' grapes after 2 months at $0{ }^{\circ} \mathrm{C}$ with $2 \% \mathrm{O}_{2}+5 \% \mathrm{CO}_{2}$ or $10 \% \mathrm{CO}$ in air.

Tolerance to ICA has been reported for

Table 1. Soluble solids concentration (SSC) and rachis browning of 'Thompson Seedless' grapes after 4.5 days at $20{ }^{\circ} \mathrm{C}$ or 6 days at $5{ }^{\circ} \mathrm{C}$ in insecticidal atmospheres.

\begin{tabular}{|c|c|c|c|c|}
\hline \multicolumn{2}{|c|}{ Atmosphere } & \multirow{2}{*}{$\begin{array}{l}\text { SSC } \\
(\%)\end{array}$} & \multirow{2}{*}{$\begin{array}{c}\text { Rachis } \\
\text { browning } 1^{\mathrm{z}}\end{array}$} & \multirow{2}{*}{$\begin{array}{c}\text { Rachis } \\
\text { browning } 2^{z} \\
\end{array}$} \\
\hline $\mathrm{O}_{2}(\%)$ & $\mathrm{CO}_{2}(\%)$ & & & \\
\hline \multicolumn{5}{|c|}{$20^{\circ} \mathrm{C}$} \\
\hline 21 & 0.03 & $18.0 \mathrm{a}$ & $2.5 \mathrm{a}^{\mathrm{y}}$ & $3.7 \mathrm{a}$ \\
\hline 0.5 & 35 & $17.6 \mathrm{a}$ & $1.4 \mathrm{~b}$ & $2.4 \mathrm{~b}$ \\
\hline 0.5 & 45 & $17.8 \mathrm{a}$ & $1.4 \mathrm{~b}$ & $2.0 \mathrm{~b}$ \\
\hline 0.5 & 55 & $16.9 \mathrm{bc}$ & $1.7 \mathrm{~b}$ & $2.2 \mathrm{~b}$ \\
\hline 0 & 100 & $16.6 \mathrm{c}$ & $1.6 \mathrm{~b}$ & $2.4 \mathrm{~b}$ \\
\hline & & $*$ & $* *$ & $* *$ \\
\hline \multicolumn{5}{|c|}{$5^{\circ} \mathrm{C}$} \\
\hline 21 & 0.03 & 19.5 & $0.5 \mathrm{~b}$ & 0.8 \\
\hline 0.5 & 35 & 19.8 & $0.6 \mathrm{ab}$ & 1.0 \\
\hline 0.5 & 45 & 19.8 & $0.9 \mathrm{a}$ & 1.1 \\
\hline 0.5 & 55 & 19.9 & $0.5 \mathrm{~b}$ & 1.0 \\
\hline \multirow[t]{2}{*}{0} & 100 & 19.1 & $0.9 \mathrm{a}$ & 1.2 \\
\hline & & NS & $*$ & NS \\
\hline
\end{tabular}

$\overline{{ }^{2} \text { Rachis browning evaluation times: } 1=\text { upon removal from insecticidal controlled atmosphere; } 2=\text { after } 3}$ days at $0^{\circ} \mathrm{C}$ in air.

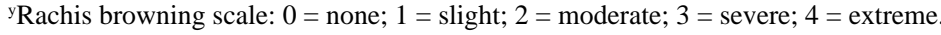

ss, ${ }^{*}, * *$ Nonsignificant or significant at $P \leq 0.05$ and 0.01 . 

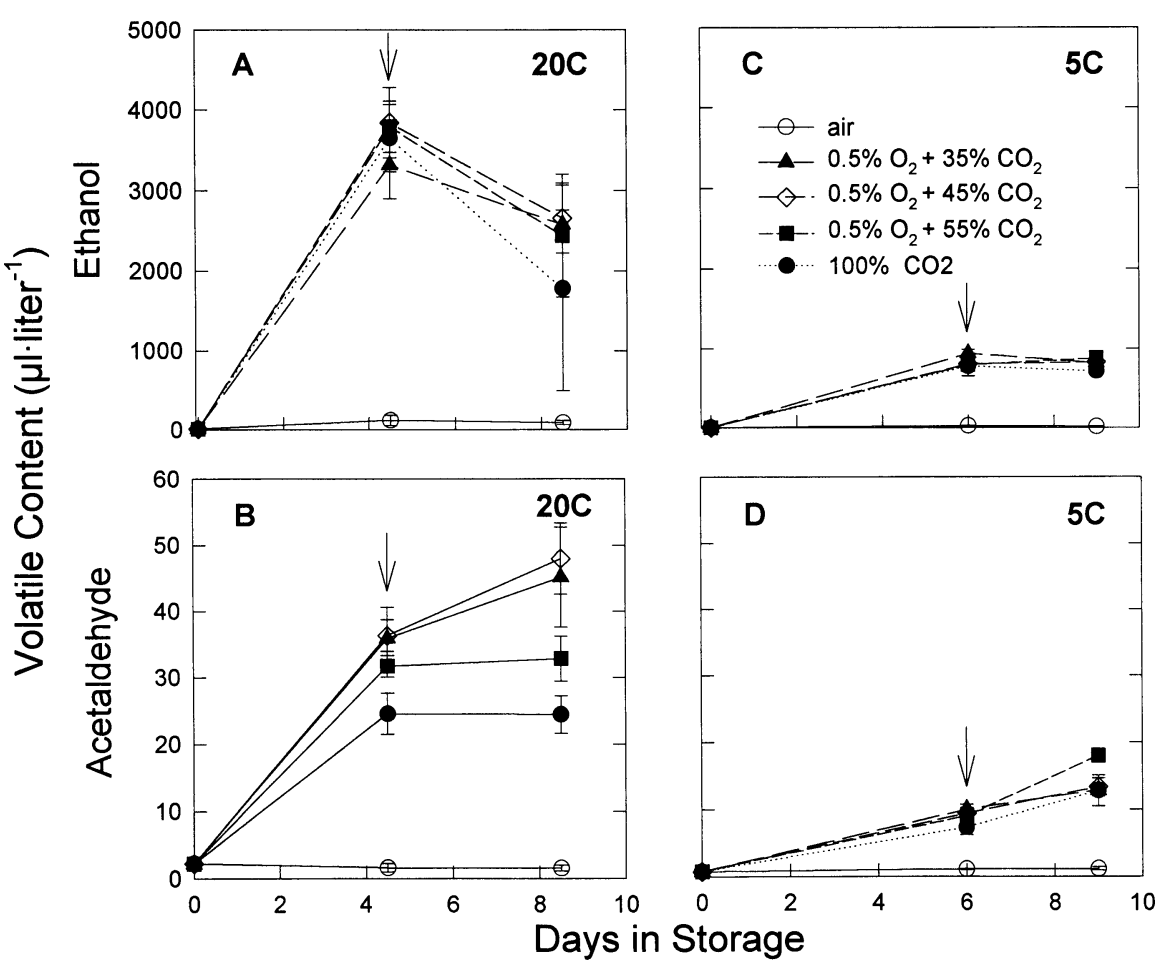

Fig. 1. Ethanol and acetaldehyde content of table grapes after insecticidal controlled-atmosphere treatments at (A and B) $20^{\circ} \mathrm{C}$ and $\left(\mathbf{C}\right.$ and D) $5^{\circ} \mathrm{C}$. Volatiles measured in headspace gas after incubation of $5 \mathrm{~mL}$ of juice in a sealed vial. Arrows denote transfer to air at $0^{\circ} \mathrm{C}$. Vertical bars represent SD.

other commodities (Ke et al., 1994; Pesis et al., 1994; Yahia et al., 1992). An important benefit of high- $\mathrm{CO}_{2}$ treatments is the fungistatic action of $\mathrm{CO}_{2}$ levels $>15 \%$ (Wells and Uota, 1970). Treatment with ICA may provide sufficient decay control to allow a reduction in the need for $\mathrm{SO}_{2}$ fumigations for rapidly marketed fruit. Also, although grapes treated in this study were not fumigated with $\mathrm{SO}_{2}$, other experiments have indicated that $\mathrm{SO}_{2}$ fumigation would be compatible with ICA treatments (unpublished data).

Anaerobically produced volatiles, such as acetaldehyde and ethanol, accumulated under low- $\mathrm{O}_{2}$ and high- $\mathrm{CO}_{2}$ atmospheres, with greater accumulation at higher temperatures (Ke and Kader, 1990; Ke et al., 1991c, 1994; Pesis et al., 1994; Saltveit and Ballinger, 1983). Our data agree with these observations (Fig. 1). Saltveit and Ballinger (1983) observed that 1 to 7 days was required to reduce the ethanol

Table 2. Consumer preference analysis of 'Thompson Seedless' grapes after 4.5 days at $20^{\circ} \mathrm{C}$ or 6 days at $5^{\circ} \mathrm{C}$ in insecticidal atmospheres plus 3 days storage in air at $0^{\circ} \mathrm{C} .{ }^{z}$

\begin{tabular}{lcll}
\hline \multirow{2}{*}{ Atmosphere } & & \multicolumn{2}{c}{ Storage temp $\left({ }^{\circ} \mathrm{C}\right)$} \\
\cline { 3 - 4 } \multicolumn{2}{c}{} & \multicolumn{2}{c}{5} \\
\cline { 4 - 4 } $\mathrm{O}_{2}(\%)$ & $\mathrm{CO}_{2}(\%)$ & & \multicolumn{2}{c}{ Rating } \\
\hline 21 & 0.03 & $2.6 \mathrm{a}^{\mathrm{y}}$ & $2.9 \mathrm{ab}^{\mathrm{x}}$ \\
0.5 & 35 & $3.3 \mathrm{ab}$ & $2.9 \mathrm{ab}$ \\
0.5 & 45 & $3.4 \mathrm{ab}$ & $3.0 \mathrm{ab}$ \\
0.5 & 55 & $4.3 \mathrm{~b}$ & $2.3 \mathrm{a}$ \\
0 & 100 & $3.4 \mathrm{ab}$ & $3.3 \mathrm{~b}$ \\
\hline
\end{tabular}

${ }^{2}$ Newell-MacFarlene two-factor ranked analysis of variance at $P \leq 0.05$.

${ }^{\mathrm{y}} 1=$ most preferred; $6=$ least preferred (data for one treatment not presented).

${ }^{\mathrm{x}} 1=$ most preferred; $5=$ least preferred. content in 'Carlos' grapes by $50 \%$ during storage at $0{ }^{\circ} \mathrm{C}$. Pesis et al. (1994) observed a 10- to 50-fold greater concentration of ethanol compared with acetaldehyde in apples (Malus domestica Borkh.) after 1 week of storage at $20^{\circ} \mathrm{C}$ following exposure to high $\mathrm{CO}_{2}$. Reduction in acetaldehyde has been attributed to volatilization or further metabolism by the fruit (De Pooter et al., 1983, 1987; Mattheis, 1991). Our results for storage in air at $0{ }^{\circ} \mathrm{C}$ after ICA indicate a minimal reduction in ethanol and no change or an increase in acetaldehyde concentration. The lack of reduction in acetaldehyde and the minimal reduction in ethanol upon transfer to air at $0{ }^{\circ} \mathrm{C}$ may have been related to the low temperature $\left(0^{\circ} \mathrm{C}\right)$ and the short time in air storage (Fig. 1).

Consumer preference was negatively affected by treatment with $0.5 \% \mathrm{O}_{2}+55 \% \mathrm{CO}_{2}$ at $20{ }^{\circ} \mathrm{C}$. While acetaldehyde content was lower than in fruit treated with $35 \%$ or $45 \%$ $\mathrm{CO}_{2}$, the SSC for grapes treated with $0.5 \% \mathrm{O}_{2}$ $+55 \% \mathrm{CO}_{2}$ also was significantly lower than control fruit. Ke et al. (1991c) demonstrated in a range of fruits that the ethanol content that would cause slight off flavor increased with

Table 3. Percent mortality of western flower thrips, pacific spider mites, and omnivorous leafrollers after 6 days in insecticidal atmosphere at $5{ }^{\circ} \mathrm{C}$.

\begin{tabular}{|c|c|c|c|c|c|c|}
\hline & & \multicolumn{2}{|c|}{$\mathrm{WFT}^{\mathrm{z}}$} & \multicolumn{2}{|c|}{$\mathrm{PSM}^{\mathrm{z}}$} & \multirow{3}{*}{$\begin{array}{c}\text { OLR }^{z} \\
\text { Pupae } \\
(\mathrm{n}=342)\end{array}$} \\
\hline \multicolumn{2}{|c|}{ Atmosphere } & \multirow{2}{*}{$\begin{array}{c}\text { Larvae } \\
(\mathrm{n}=84)\end{array}$} & \multirow{2}{*}{$\begin{array}{c}\text { Adults } \\
(\mathrm{n}=125)\end{array}$} & \multirow{2}{*}{$\begin{array}{c}\text { Larvae } \\
(\mathrm{n}=633)\end{array}$} & \multirow{2}{*}{$\begin{array}{c}\text { Adults } \\
(\mathrm{n}=608)\end{array}$} & \\
\hline $\mathrm{O}_{2}(\%)$ & $\mathrm{CO}_{2}(\%)$ & & & & & \\
\hline 21 & 0.03 & $9^{y}$ & 11 & 6 & 15 & 26 \\
\hline 0.5 & 35 & 86 & 99 & 71 & 67 & 99 \\
\hline 0.5 & 45 & 98 & 100 & 93 & 94 & 100 \\
\hline 0.5 & 55 & 100 & 100 & 100 & 100 & 100 \\
\hline 0 & 100 & 100 & 100 & 100 & 100 & 100 \\
\hline
\end{tabular}

${ }^{2}$ WFT $=$ western flower thrips; PSM = pacific spider mite; OLR = omnivorous leafroller.

${ }^{y}$ Data represent mean of three replications. the SSC of the commodity. According to Ke's data, a SSC of $17 \%$ and ethanol at $3800 \mu \mathrm{L} \cdot \mathrm{L}^{-1}$, which was present in fruit treated with $55 \%$ $\mathrm{CO}_{2}$ at $20^{\circ} \mathrm{C}$, could result in slight off flavor. This accumulation likely affected consumer preference for these fruit. However, preference for grapes treated with $100 \% \mathrm{CO}_{2}$, which also had lower SSC and high volatile content, was not significantly different from that for the air control (Table 2).

At $5^{\circ} \mathrm{C}$, there was little difference in consumer preference for treated grapes. Fruit treated with $0.5 \% \mathrm{O}_{2}+55 \% \mathrm{CO}_{2}$ were preferred over grapes treated with $100 \% \mathrm{CO}_{2}$. Fruit treated with $55 \% \mathrm{CO}_{2}$ had the highest acetaldehyde content at the time of the sensory evaluation. Small amounts of acetaldehyde and ethanol enhance sensory quality (Paz et al., 1981; Pesis and Frenkel, 1989), while high concentrations may be detrimental to sensory quality (Smagula and Bramlage, 1977). Sensory quality of strawberries (Fragaria $\times$ ananassa Duch.) was unaffected by ICA treatments with $0 \% \mathrm{O}_{2}$ and $50 \%$ or $80 \% \mathrm{CO}_{2}$ for up to 6 days at 0 or $5^{\circ} \mathrm{C}$, providing the fruit were stored at $0{ }^{\circ} \mathrm{C}$ in air for 10 days before sensory analysis (Ke et al., 1991a). These data indicate the importance of time after treatment to the outcome of sensory analysis.

Our data indicate that some of the ICA tested show promise for control of OLR pupae, WFT adults and larvae, and PSM adults and larvae within 4.5 days at $20^{\circ} \mathrm{C}$ or 6 days at $5{ }^{\circ} \mathrm{C}$. Grape quality after 6 days at $5{ }^{\circ} \mathrm{C}$ was not negatively affected by the ICA treatments. However, at $20{ }^{\circ} \mathrm{C}$, although ICA-treated grapes were not significantly different from air-stored grapes in quality, the high amount of rachis browning, likely due to storage temperature, would make such a treatment unacceptable commercially, while treatment at 5 ${ }^{\circ} \mathrm{C}$ appears promising.

\section{Literature Cited}

Aharoni, Y., P. Hartsell, J.K. Stewart, and D.K. Young. 1979. Control of western flower thrips on harvested strawberries with acetaldehyde in air, $50 \%$ carbon dioxide or $1 \%$ oxygen. J. Econ. Entomol. 72:819-822.

Aharoni, Y., J.K. Stewart, and D.G. Guadagni. 1981 Modified atmospheres to control western flower thrips on harvested strawberries. J. Econ. Entomol. 74:338-340.

Batchelor, T.A., R.L. O'Donnell, S.P. Foster, and J.J. Roby. 1985. Postharvest insect disinfestation of fresh asparagus in Waikato-1984 Spring season and 1985 autumn season. DSIR Internal Rpt., New Zealand. 
Carpenter, A., S. Kerr, R. Lill, D. Irving, V. Corrigan, and L-H. Cheah. 1993. Recent developments in the use of controlled atmospheres for postharvest disinfestation. Proc. Austral. Postharvest Conf. The Univ. of Queensland, Gatton College, Australia. Sept. 1993. p. 295-301.

Carpenter, A. and M.A. Potter. 1994. Controlled atmospheres, p. 171-198. In: J.K. Sharp and G.J. Hallman (eds.). Quarantine treatments for pests of food plants. Westview Press, Boulder, Colo.

Cimino, A. and P. Zanangeli. 1990. ULO storage of table grapes. Qualita del Prodotti Ortofrutticoli Postraccolta. Fondazione Cesena Agricultura, Cesena:99-102.

Claypool, L.L. and F.W. Allen. 1947. Modified atmospheres in relation to the transportation of deciduous fruits. Proc. Amer. Soc. Hort. Sci. 49:92-98.

Davis, P.L. and W.G. Chace, Jr. 1969. Determination of alcohol in citrus juice by gas chromatographic analysis of headspace. HortScience 4:117-119.

De Pooter, H.L., J.P. Montens, G.A. Willaert, P.J. Dirinck, and N.M. Schamp. 1983. Treatment of 'Golden Delicious' apples with aldehydes and carboxylic acids: Effect on the headspace composition. J. Agr. Food Chem. 31:813-818.

De Pooter, H.L., M.R. Van Achker, and N.M Schamp. 1987. Aldehyde metabolism and the aroma quality of stored 'Golden Delicious' apples. Phytochemistry 26:89-92.

Fleurat-Lassard, F. 1990. Effects of modified atmospheres on insects and mites infesting stored products, p. 21-38. In: M. Calderon and R. Barkai-Golan(eds.). Food preservation by modified atmospheres. CRC Press, Boca Raton, Fla.

Harvey, J.M. and M. Uota. 1978. Table grapes and refrigeration: Fumigation with sulfur dioxide. Intl. J. Refrigeration 1:167-171.

Jayas, D.S., B. Khangura, and N.D.G. White. 1991. Controlled atmosphere storage of grains. Postharvest News Info. 2:423-427.

Kader, A.A. and D. Ke. 1994. Controlled atmospheres, p. 223-236. In: R.E. Paull and J.W.
Armstrong (eds.). Insect pests and fresh horticultural products: Treatments and responses. CAB Intl., U.K.

Ke, D., F. El-Wazir, B. Cole, M. Mateos, and A.A. Kader. 1994. Tolerance of peach and nectarine fruits to insecticidal controlled atmospheres as influenced by cultivar, maturity, and size. Postharvest Biol. \& Technol. 4:135-146.

Ke, D., L. Goldstein, M. O'Mahony, and A.A. Kader. 1991a. Effects of short-term exposure to low $\mathrm{O}_{2}$ and high $\mathrm{CO}_{2}$ atmospheres on quality attributes of strawberries. J. Food Sci. 56:50-54.

Ke, D. and A.A. Kader. 1990. Tolerance of 'Valencia' oranges to controlled atmospheres as determined by physiological responses and quality attributes. J. Amer. Soc. Hort. Sci. 115:779-783.

Ke, D. and A.A. Kader. 1992. Potential of controlled atmospheres for postharvest insect disinfestation of fruit and vegetables. Postharvest News Info. 3:31N-37N.

Ke, D., L. Rodriguez-Sinobas, and A.A. Kader. 1991b. Physiological responses and quality attributes of peaches in low oxygen atmospheres. Sci. Hort. 47:295-303.

Ke, D., L. Rodriguez-Sinobas, and A.A. Kader. 1991c. Physiology and prediction of fruit tolerance to low-oxygen atmospheres. J. Amer. Soc. Hort. Sci. 116:253-260.

Laszlo, J.C. 1985. The effect of controlled atmosphere on the quality of stored table grapes. Deciduous Fruit Grower 35:436-438.

Mattheis, J.P., D. Buchanan, and J.K. Fellman. 1991. Change in apple fruit volatiles after storage in atmospheres inducing anaerobic metabolism. J. Agr. Food Chem. 39:1602-1605.

Nelson, K.E. 1969. Controlled atmosphere storage of table grapes. Proc. Natl. Calif. Res. Conf., Michigan State Univ., Hort. Rpt. 9:69-70.

Nelson, K.E. 1979. Harvesting and handling California table grapes for market. Bul. 1913. ANR Publications, Univ. of California, Oakland.

Newell, G.J. and J.D. MacFarlane. 1987. Expanded table for multiple comparison procedures in the analysis of ranked data. J. Food Sci. 52:1721.

Paz, O., H.W. Janes, B.A. Prevost, and C. Frenkel.
1981. Enhancement of fruit sensory quality by post-harvest applications of acetaldehyde and ethanol. J. Food Sci. 47:270-273.

Pesis, E., C. Ampunpong, B. Shusiri, and E.W. Hewett. 1994. Enhancement of ethylene and $\mathrm{CO}_{2}$ production in apple fruit following shortterm exposure to high $\mathrm{CO}_{2}$. Postharvest Biol. \& Technol. 4:309-317.

Pesis, E. and C. Frenkel. 1989. Acetaldehyde vapors influence postharvest quality of table grapes. HortScience 24:315-317.

Prange, R.K. and P.D. Lister. 1992. Controlledatmosphere effects on blueberry maggot and lowbush blueberry fruit. HortScience 27:10941096.

Saltveit, M.E., Jr., and W.E. Ballinger. 1983. Effects of anaerobic nitrogen and carbon dioxide atmospheres on ethanol production and postharvest quality of 'Carlos' grapes. J. Amer. Soc. Hort. Sci. 108:462-465.

Smagula, J.M. and W.J. Bramlage. 1977. Acetaldehyde accumulation: Is it a cause of physioloical deterioration of fruit? HortScience 12:200-203.

Soderstrom, E.L. and D.G. Brandl. 1990. Controlled atmospheres for the preservation of tree nuts and dried fruit, p. 83-92. In: M. Calderon and R. Barkai-Golan (eds.). Food preservation by modified atmospheres. CRC Press, Boca Raton, Fla.

Wells, J.M. and M. Uota. 1970. Germination and growth of five fungi in low-oxygen and highcarbon dioxide atmospheres. Phytopathology 60:50-53.

Yahia, E.M., K.E. Nelson, and A.A. Kader. 1983. Postharvest quality and storage life of grapes (Vitis vinifera L.) as influenced by adding carbon monoxide to air or controlled atmospheres. J. Amer. Soc. Hort. Sci. 108:1067-1071.

Yahia, E.M., M. Rivera, and O. Hernandez. 1992. Responses of papaya to short-term insecticidal oxygen atmosphere. J. Amer. Soc. Hort. Sci. 117:96-99.

Yokoyama, V.Y., G.T. Miller, and J.M. Harvey. 1987. Development of oriental fruit moth (Lepidoptera: Tortricidae) on a laboratory diet. J. Econ. Entomol. 80:272-276. 